\title{
A role for government in regional development
}

paper presented at the $22^{\text {nd }}$ IMP Conference in Milan 7-9 September 2006

\section{Peter E Parker}

Kristianstad University

29188 Kristianstad

Sweden

Peter.parker@e.hkr.se

\section{Christer Ekelund}

Kristianstad University

Keywords: regional development, government, strategic networks

\begin{abstract}
The paper argues that regional development initiatives are important. However, development initiatives are complex projects and the management of these projects warrants careful consideration. The paper takes a closer look at the nature of managerial problems in regional development projects. Drawing on literature on iterative project management, we analyze managerial issues that regional development initiatives must confront. The analysis leads to set of suggestions in as to how these managerial challenges might be addressed. Particularly we suggest that a redefinition of roles and forms in regional development initiatives could substantially increase the ability of agencies to achieve results and communicate them.
\end{abstract}




\section{Introduction}

Regional development initiatives funded by the $E C$ and by national and regional governments channel significant funds each year into attempting to create employment and economic growth. The Swedish Agency for Economic and Regional Growth, NUTEK, estimates that in the first years of the new millennium approximately 10 billion Swedish crowns (more than 1 billion Euros) were annually channeled into regional development projects in Sweden. EC structural funds, national and regional governmental agencies and private enterprises each contribute roughly a third of the total investment (NUTEK 2004). The enormous interest in promoting regional development is understandable and may rest on solid theoretical grounds. There are, however also well-known and serious practical difficulties to be addressed in publicly financed efforts to promote regional development. Difficulties in achieving and assessing the results in these initiatives entail the risk that even a well-founded policy may be undermined.

Many regional development initiatives in Sweden make use of network-based approaches, that is, they seek to promote network development as a means of knowledge transfer and development in business. While this is reasonable given that networks may provide important conduits of knowledge, surprisingly little is known about how these initiatives actually affect businesses and their existing networks. It seems safe to say, however, that spectacular successes are rather few. The general impression is that these initiatives encounter substantial difficulties in implementation (Gullander, et al. 2004; NUTEK and VINNOVA 2002). This seems to be the case not only Sweden but also in the EC as a whole. It is probable therefore that there are problems in the basic structure of these initiatives.

This paper briefly reviews some theoretical foundations of regional development policies. We then seek to identify some key managerial problems in publicly financed regional development initiatives and analyze them in the light of theory on complex projects.

Based on this analysis we offer suggestions as to how management practices might be shifted toward a more agile approach in order to address what we see as key problem areas.

\section{A theoretical basis for government involvement in regional development}

Before discussing managerial problems of regional development initiatives it may be appropriate to begin by addressing the question as why regional development initiatives are needed at all? An understanding of the underlying arguments for publicly financed regional development initiatives also provides a better understanding of the challenges involved. A thorough review of policy discussions and theory in this field falls well beyond the scope of this paper. However, broad discussions of policy in this area point to two important underlying assertions: Firstly, markets provide insufficient mechanisms for generating and transferring knowledge. Secondly, that knowledge development is central to economic development (Hallin and Östhol 2004; Metcalfe 1997).

The assertion that markets provide insufficient mechanisms for the transfer and development of knowledge relies perhaps primarily on arguments deriving from the particular nature of knowledge as an economic good. The market imperfection (failure) approach suggests that firms underinvest in knowledge development for primarily two reasons. Firstly, firms have difficulties in estimating returns on investments in new knowledge. This entails a certain conservatism. Secondly, firms have difficulties in capturing returns on knowledge they develop, as certain kinds of knowledge may be circulated at little cost and one person's use of the knowledge does not preclude another person's. The possibility of 'free' circulation of knowledge is important in many respects but poses a problem for individual firms seeking to capture returns on investments in knowledge development. Moreover, knowledge itself is difficult to sell as disclosing it to a potential customer effectively negates the need for the customer to buy it. Difficulties in estimating and capturing returns lead firms to invest less in knowledge development than may be beneficial from a societal perspective. Simply phrased, markets provide insufficient mechanisms to promote and transfer knowledge.

The arguments on the insufficiency of market mechanisms for the creation and transfer of knowledge acquire increased significance in the light of the widespread belief that the ability to and incentive to innovate, i.e. commercialize knowledge, is a key component of firm and regional competitiveness. 
Thus for instance in Porter's influential work, regional development depends on forms of rivalry, network connections of firms and closeness to demanding consumers as well as the skill of employees as key ingredients of a dynamic development (Porter 1990). Dynamic regions are thus characterized by firms having high quality communication with front-line suppliers and demanding customers and firms compete by drawing on available knowledge in the region in creating improved products and processes (Saxenian 2000).

Given that markets provide insufficient mechanism for the development of knowledge and that knowledge is a key resource in regional development, it is natural that governments should take a keen interest in promoting effective forms of knowledge transfer and development in business. In principle, governments should be able to do something about this situation e.g. help to create nonmarket mechanisms for transfer and development of knowledge or subsidize investments in new knowledge.

The most commonly espoused means of going about stimulating knowledge development in business is to promote the creation of regional business networks. The underlying premise is that networks provide important non-market means of transferring knowledge between organizations. By promoting the development of regional business networks governments may augment knowledge transfer and development in the region and thereby stimulate economic development. By promoting better connectivity between firms, research facilities and other agencies regions hope to facilitate innovation and long-term competitiveness.

We accept the idea that stimulating networks is a feasible way of approaching this issue. That is, we accept as fact that networks provide the important non-market mechanisms for the development and transfer of knowledge (Larson 1992; Parker 2004; Ring and Van de Ven 1994). The problem we are concerned with is the management and organization of efforts to promote appropriate networks.

\section{Problems of management}

Governmental agencies have a potentially important role in facilitating regional development primarily perhaps by supporting non-market means of knowledge development and transfer. Realizing this potential is however not a trivial task. In this section we seek to outline four major managerial issues confronting government backed regional development initiatives. The list of challenges is not exhaustive but seeks to capture key issues confronting these initiatives.

A first problem, often noted by economists is the risk that publicly financed initiatives crowd out private financing. In other words, public financing simply replaces private financing for projects that would have taken place anyway. This is perhaps more often a concern when public financing is used to stimulate product or process development in individual firms but may also occur for instance in education initiatives. The crowding out of private financing is a concern because the addition of public resources achieves no additional effects in terms of development but may introduce new administrative problems both for firms and governmental agencies. Empirical evidence on crowding out is ambiguous yet the concern is real (David, et al. 2000). Clearly regional development initiatives must seek to create regional resources over and beyond what would have normally created by private actors.

While crowding out of private financing is an important issue, it seems that many regional development initiatives actually suffer from too little, rather than too much business interest. It has often proven difficult for publicly financed initiatives to create sufficient business involvement in the creation of regional resources. The reason for this lack of involvement is not altogether clear. In part the problem seems to stem from that regional development initiatives have to strike a fine balance between creating too much direct interest and too little. In other words, to avoid issues of crowding out private financing, too much business interest, initiatives may focus on areas of too little business interest i.e. where business sees little direct potential for gainful development and therefore do not take an active part. There have been recurring warnings in reports from various initiatives on failures to create this involvement both in Sweden (Berggren C 1998; ITPS 2004b) and in the EC structural funds generally (NUTEK 2005). In a summary report NUTEK notes the lack of business involvement in EC funded regional development initiatives generally. As the agency notes somewhat laconically; "the parties to be developed should take part in the development project" (NUTEK 2005). The second 
problem that needs to be addressed in the management of regional development issues is therefore the creation of adequate business involvement. Regional development ultimately takes place through businesses; returns are realized and employment is created in businesses. It is to be expected that coordination with existing business is a pivotal element of most regional development initiatives.

Part of the problem in creating business involvement seems to be related to the large-scale bureaucratic procedures used in many regional development initiatives. These procedures are developed to assure accountability in the use of public funding. As such, they are commendable. However, the system of bureaucratic control is singularly ill adapted to creating innovative exchanges and increased connectivity that the initiatives seek to promote. The problem is not specific to the publicly financed initiatives; it has more to do with the nature of knowledge development. Traditional top-down planning and control mechanisms simply are not effective means of promoting knowledge creation and innovation (Christensen, et al. 1997). In our experience the bureaucracy involved in these regional development initiatives which serves to assure that financing is used correctly is perceived as both burdensome and relatively unrelated to actual practice by the businesses involved. This imposition of irrelevant bureaucratic procedures also undermines the trust necessary for developmental projects. Thus, the untimely imposition of bureaucratic control is itself a major managerial issue for regional development initiatives.

Perhaps the most serious management problem of regional development initiatives is the inability to demonstrate positive effects. This may in part be due to inherent difficulties in measuring diffuse developmental outcomes but probably also signals serious problems of implementation, such as the difficulties noted in the preceding. An extensive independent review of the impact of the impact of structural funds in Sweden 1995-2000 finds no quantifiable affect whatsoever in relation to goal variables such per capita income, employment rate or proportion of population of working age. Moreover, the report finds no support linking EC funding to any of the 15 intermediary variables measuring different aspects of business dynamism, development of skills and labor market or the attractiveness of the region as a place of work or recreation. It is the conclusion of the ITPS, the Swedish Institute for Growth Policy Studies, that this should be interpreted as serious warning signal with respect to the implementation of the programmes. However, the agency also states there is a need to develop means of evaluation. (ITPS 2004a). Both difficulties in achieving results and difficulties in measuring them may contribute to the lack of visible impact of EC structural funds in Sweden. However, the inability to demonstrate positive outcomes is in any case a serious managerial problem.

The list of managerial problems confronting regional development initiatives may seem formidable. Some of these challenges are specific to these kinds of initiatives i.e. the problem of crowding out but most of the other issues are familiar problems of business studies. Existing research has a great deal to say about how these challenges may be met. In the following sections, we seek to elaborate an understanding of the managerial problems discussed here. Drawing on research from business network studies and from iterative project management, we seek to provide means of addressing all of these issues, at least in part.

A possible solution, it is argued, lies in creating a more active and responsible role for regional government and in the use of ongoing process evaluation informed by business network theory.

\section{Complexity of regional development initiatives}

Regional development projects come in different shapes and sizes. Nonetheless, we believe that many of these initiatives are faced by similar types of challenges. Such projects are complex in at least two respects.

Firstly, there is knowledge gap between the regional government or agency and the firms that take part in the project. This gap derives from that the publicly financed agencies and partaking firms are part of different fields of activity with different rules and priorities. The parties may be assumed to have limited knowledge of the particular realities of the other. Communication across this gap is made more difficult by the complicated relation between aims and means of the two parties. Firms may be assumed to take part in regional development initiatives based on self-interest. The primary question is thus if the initiative creates resources for the firm. For a regional development agency business interest is a means for aims that are perhaps less easy to communicate such as regional knowledge 
transfer and development. In a sense, regional development agencies and firms have inverse views on what constitutes project aims. Regional development agencies want to see the development of regional resources. Firms are only interested to the extent that these resources provide means to achieving their business aims. A regional development initiative can therefore be said to be complex with respect to the setting of project requirements.

Secondly, development initiatives are complex in the sense that there is considerable uncertainty as to how to achieve the aims set in the project. For instance, a regional development initiative may aim to achieve increased employment in the long term. The appropriate means of achieving this aim is far from clear-cut. As in any development project the actors need to actively explore different possibilities. The set of possibilities which will be explored is not given. Rather, the means used in a regional development project must depend on a complex weave of autonomous actors whose priorities may change over time. A regional development initiative may therefore be said to be complex in a process or technological sense.

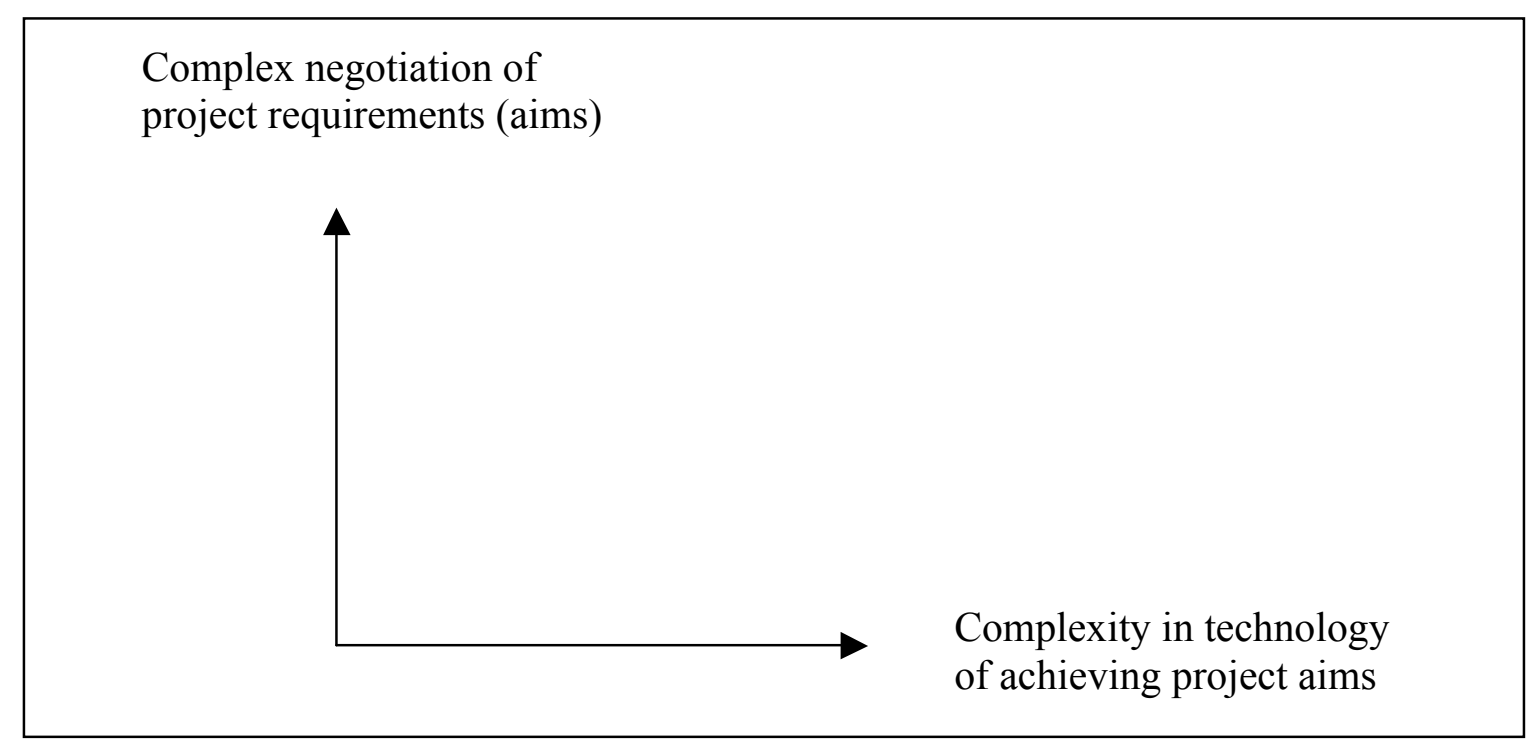

Figure 1: two dimensions of project complexity

If it is correct that regional development projects are complex in these respects than this has implications for how they should be managed. In complex projects, traditional means of planning and control based on predictability of means and results quickly lose their relevance. Defining necessary requirements for the end products is almost impossibly time consuming due to knowledge gaps between parties. Even if it is possible to set a reasonable set of requirements these will be necessarily be subject to change as the project develops and new areas are explored. Detailed and long term planning therefore becomes useless and may quite possible hinder potential development (Blomberg 2003). Unfortunately, it seems to be common that repeated failures of projects to achieve their specified ends tends to strengthen calls for planning and control rather than lead to a questioning of methods (Tjäder and Söderlund 2001). The logic of bureaucratic control is so highly ingrained, even in project management that at times it becomes difficult to question. We believe a large part of the problems confronting regional development initiatives may be understood to stem from the collision of bureaucratic control systems and a complex reality. Bureaucratic logic is pervasive in regional development initiatives. For instance, competence-raising programs may be initiated in hopes that a higher level of competence will generate a higher incomes or more productive work. But the question of how the education provided is actually put to use will fall outside of the scope of the program. Agencies to promote business development may be initiated and run without any built in feedback as to actual improvements for businesses. This is a logic that enables us to spend billions of Euros on laudable projects that achieve no demonstrable effect. 


\section{Managing complex projects}

In the last ten years, there has been an elaboration of management theories for handling complex projects. This field was given important impetus from experience in software development where markets and technology have been developing rapidly creating uncertainty both in terms of what the developers can deliver and the best ways of solving particular problems. In this situation, extensive or long-term planning is perceived as counter-productive. Iterative or agile project management is held to be an alternative that allows both better exploration and learning while meeting needs for customer or management control e.g. (Chin 2004; Highsmith 2004; Schwaber 2004). Basic principles of this school of management include:

1. Product owners buy functionality in direct negotiation with team members

2. Since there is considerable uncertainty in the development process, functionality is broken down into deliverable increments. These are kept reasonably short so that the parties can make commitments and set priorities with some degree of confidence.

3. Each iterative cycle begins with a negotiation as to priorities of the product owner and what the team can commit itself to deliver. Each iterative cycle ends with a review of delivered functionality. This enables assessment of progress and provides a basis for new negotiations.

4. Teams manage themselves. Once the priorities are set at the start of a cycle the team finds its own ways of exploring and meeting requirements. This encourages exploration and makes the best possible use of existing knowledge. Self-managed teams should be of reasonable size, 6-10 members, so that high quality communication is possible in dealing with complex problems. Larger projects are possible but as size increases different strategies need to be employed to handle interconnections between groups.

5. Although teams are self-managing it is important that there is a role guarding and tracking the process itself. This knowledge is used to improve the process of negotiations at the start of each iterative cycle as well as a basis for coaching teams.

This iterative form of project management is designed to make the best possible use of the disparate knowledge of different stakeholders in the project. It attempts to do so by creating the best possible forms of communication given a high level of uncertainty with respect to requirements and technology. The key mechanism is to communicate about tangible results of delivered functionality rather than about ideas about possible results. The process contains mechanisms that allow the project to evolve as new areas are explored without loss of control. On the contrary, a sense of control is usually increased by periodic delivery and demonstration of functionality and the higher quality communication this enables.

While software development undoubtedly has particularities, the basic principles underlying iterative project management are not specific to this field. The same principles can be usefully applied to other complex projects and particularly those where there is a high level of uncertainty in the two dimensions we have discussed i.e. in the specification of requirements and in the technology of meeting these requirements. In the following section, we will attempt to show that a more agile approach to regional development is possible and advantageous. We argue that this approach would alleviate the managerial problems that regional development initiatives suffer from.

\section{More agile regional development projects}

A first step and critical step in creating better management practices is to instigate a role of product owner. This is a critical part of creating better communication about requirements in the project and thus providing focus. The product owner is responsible for defining functional requirements to be achieved in the project and for setting priorities between these functions. The product owner is also responsible for negotiations with the team (network of firms) as to reasonable commitments in a given cycle of iteration. Creating a viable product owner role in a regional development initiative is probably the single most difficult task. The role is not a simple one. The product owner needs to have business expertise and political accountability as he or she is negotiating on behalf of the region. However, the main problem is not one of competence; the business expertise required will most likely be purchased in the form of consultancy. The difficult problem is perhaps that the product owner must have a 
mandate to conduct real negotiations on project focus and to be able to terminate projects. In short, the product owner needs to be a competent buyer and have mandate to make relevant decisions.

The role of the product owner is to define the functionality that he or she wishes to have. This task is difficult and will require consulting expertise in the field. Consider a hypothetical example in which a particular regional government has decided that supplier firms in the region are lagging behind. It is the perception of the regional government that the suppliers lack the ability to coordinate and deliver systems to larger customers. If this competence is not developed, supplier firms will lag behind further and jobs will be lost. The product owner also realizes, in consultation with local expertise that the suppliers must be able to develop this ability without counting on direct support from large customer firms. It is important to realize at this stage that the product owner lacks the competence to plan how regional development is to be achieved. In fact, this is probably impossible given the complexity of the project. Trying to dictate the organization or activities necessary to achieve the desired functionality is likely to be counterproductive. Instead, the product owner contacts a newly retired businessperson turned consultant who has substantial experience of purchasing in larger firms and has a network of contacts among suppliers. Using the consultant's expertise and network a team of eight or so supplier firms is selected to make up a project team.

In the next step, the product owner and team negotiate. After a day of hard work, they agree on a list of requirements consisting of a set of competencies that the firms will develop and demonstrate in the course of the project. The project must be in accordance with the interests of the businesses involved, they have to see business potential. Achieved competencies must also, in the product owner's view, provide a foundation for future business and regional development. The end goal of the project is that the firms should develop into proficient systems suppliers. However, since this involves quite a bit of uncertainty. the goal is broken down into three basic functional increments and each of these is broken down in a set of requirements. For the sake of example, perhaps the following increments could be imagined:

1. Competence in integrating technical solutions is acquired in the network of firms: The suppliers will conduct an analysis of a particular system in a larger customer firm and work together to find an alternate technical solution for this system that improves substantially on the current one. This will be reviewed at the end of the first increment by an external consultant and by the customer firm.

2. Partnering competence is developed in the network of firms: Forms of production and delivery of a solution require cooperative arrangements between the firms. In this case the firms work out arrangements to deliver a complex product like the one developed in the first increment. Thus, the increment requires the development of forms of cooperation and putting legal arrangements in place to enable adequate production and delivery. Functionality is demonstrated by each firm agreeing to the arrangements.

3. Market/sales competence for systems is developed in the network: The suppliers need to be able to sell improvements to large customers in an advantageous manner. This entails a marketing organization. Functionality is demonstrated by the successful meeting with new potential customer firms and a conducting of technical analysis as per increment one and making an offer for the construction and delivery of a new system in accordance with agreements developed in increment 2 .

Initially only the requirements of the first iteration are defined in a detailed manner. The product owner also sets priorities among these requirements. The team of firms negotiate what can reasonably be achieved in the first iteration given the resources available. Each cycle has a given time scale so that dialogue is maintained. The team must commit to delivering the agreed on functionality at the end of the cycle. At the end of the increment, there is a review of both results and process. There is also a renegotiation of priorities and commitments for the next iteration. Of course, either individual firms or the product owner may wish not to continue the project.

Work in each iteration is conducted completely on the terms of the partaking firms. They own the problem and they have the best knowledge of how to move the situation forward. In this work, the firms also develop their ability to solve joint problems. The firms may use the services of the business consultant but are not obligated to do so. Naturally, firms will account for their use of public resources made available to them but this is really less interesting, the interesting part is what they achieve. 
Thus, the project imposes minimum amount of bureaucracy and encourages the firms to find costefficient means of achieving the results.

Throughout the development initiative, the work process itself is observed by a third party with responsibility to track the process itself. This knowledge is used to improve the process of negotiations at the start of each iterative cycle in this project but also in subsequent ones. This provides an important basis for learning. Understanding the developmental processes in the firm is also part of assessing the development of business networks and joint problem solving ability in the participating firms. These networks and the knowledge development they enable are what constitute a regional resource.

\section{Advantages of a more agile approach}

The advantage of an iterative approach to managing regional development initiatives is that it provides means to address the serious managerial challenges.

A first, highly important advantage of the approach is that it invites business, key actors in regional development, to take part in exploring the best possible means of creating regional resources and to do so on their own terms. The emphasis on demonstrated functionality in an iterative approach helps to bridge a gap in communication about requirements. Although a regional development agency may be more concerned with the creation of resources and businesses more about results both parties have an interest in the demonstration of acquired competencies. Demonstration also allows for better communication about what the project has actually entailed. The recurring negotiations are an important means of keeping the project on track in the sense that regional interests have been achieved and that the businesses remain involved.

Secondly, the iterative approach is predicated on using small self-organizing teams committed to achieving goals that they have helped to set. It is important that the team has taken part in setting goals, this makes the best possible use of the teams knowledge at the outset and also works to create involvement and commitment to goals. The relatively small size of the team facilitates communication and coordination in solving complex problems and learning. Involvement and learning in manageable groups provide a excellent basis for dealing with challenges in complex projects.

Thirdly, since each increment ends with a demonstration of achieved functionality and since there is an observation of process there will be solid grounds for assessing regional development initiatives, even ongoing ones. Initiatives governed on these principles will be able to demonstrate tangible and relevant results.

Fourthly, the iterative approach especially when coupled with an observer function allows learning in and across projects. The observer can provide valuable input to facilitate negotiations in subsequent iterations and subsequent projects. Improving process over time should lead to significant advantages. Primarily, the product owner's competence increases over time as to the process of negotiating about developments and improve his or her assessments on possible development initiatives. Moreover, it becomes possible to make informed distinctions on what constitutes a development of a regional resource, rather than a firm resource. This provides good grounds for avoiding crowding out of private financing.

Finally, the proposed approach is light on bureaucracy. Bureaucratic procedure is in any case singularly ill suited for producing the kinds of exploration and flexibility needed in complex projects. In a more agile approach we are less interested in how funds are used and more interested in results achieved for these funds in each increment. There is therefore little need for the kind of elaborate paperwork which plagues EC funded projects.

In sum, a more agile approach to approach to regional development sets development in focus rather than bureaucratic procedure, it helps to involve key actors and demonstrate relevant results. We believe that adopting this kind of approach would be an important step in addressing serious managerial challenges in complex projects such as regional development initiatives. 


\section{Summary}

The paper takes it's starting point theoretical arguments that markets provide insufficient mechanisms for the transfer and development of knowledge. This is an important basis for regional development initiatives, particularly when takens in conjunction with evidence that regional development pivots on the ability of firms to access and develop knowledge for process and product development. These arguments point toward a potentially important role for governments in creating beneficial forms of knowledge transfer and development. However, it remains only a potential if the managerial problems hinder the realization of this role in practice.

We discuss four major managerial challenges in publicly backed regional development initiatives. This is not an exhaustive list but it does reflect important and recurring criticisms. We noted particularly; the problem of public funding crowding out private investment, the lack of business involvement in publicly backed initiatives, the problems created by weighty bureaucratic procedures and finally, the inability of regional development initiatives to demonstrate effects.

We argued that regional development issues are complex in both the sense that there is considerable uncertainty as to what is to be achieved and how to achieve it i.e. regional development initiatives are complex both with respect to the negotiation of requirements and the technology of achieving set aims. We argued that complex projects require forms of management that stimulate exploration, high quality communication and flexibility.

Relying on bureaucratic control in complex projects may unfortunately have quite detrimental effects even if these forms are used with the best of intentions. Bureaucratic control is singularly ill suited to promote knowledge development and supple coordination. Many, if not all of the managerial problems confronting regional development initiatives may be understood to spring from the meeting of bureaucratic culture and a complex reality.

Alternative approaches to managing complex projects exist. We have argued that an approach inspired by agile or iterative project management provides a useful model. These approaches build governance not primarily on controlling what activities resources may be used for, but by required recurring demonstrations of developed increments of functionality. Each increment begins with negotiations about what is possible to achieve based on previous learning of the product owner and team. This approach shifts responsibility for results to the actors involved but at the same time invites them to make the best possible use of their resources. In essence, the regional development agency is buying thin slices of a regional resource from selected groups of firms who produce it on their own terms.

The approach is premised on empowering regional governments to buy and review the development of regional resources. The approach invites businesses, key actors in regional development, to take part in exploring the best possible means of creating these regional resources and to do so on their own terms. The process allows for learning both in the individual project and across projects so that a high level of competence can be acquired with respect both to guiding the process and in negotiating requirements in each increment.

We believe that a more agile approach to managing regional development will help to address the central problems of regional development initiatives. It provides built in means of addressing key managerial challenges. This kind of approach would be an important step in establishing the legitimacy of public actors involved in regional development. 
Berggren C, Brulin G, Gustafsson L

\section{References}

1998 Från Italien till Gnosjö: Om det sociala kapitalets betydelse för livskraftiga industriella regioner. Stockholm: Rådet för Arbetslivsforskning.

Blomberg, Jesper

2003 Projektorganisationen : kritiska analyser av projektprat och praktik. Malmö: Liber

Chin, Gary ekonomi.

2004 Agile project management : how to succeed in the face of changing project requirements. New York: AMACOM.

Christensen, Søren, et al.

1997 Projektledning : att leda och lära i en ofullkomlig värld. Bjärred: Academia adacta.

David, P. A., Hall B. H., and Toole A. A.

2000 Is public R\&D a complement or substitute for private R\&D? A review of the econometric evidence. Research Policy 29(4-5):497-529.

Gullander, Staffan, Anna Öhrwall Rönnbäck, and NUTEK

2004 Produktutveckling för företag i samverkan : studie av små och medelstora svenska verkstadsföretag. Stockholm: Verket för näringslivsutveckling (NUTEK).

Hallin, Göran, and Anders Östhol, eds.

2004 På den tillväxtpolitiska agendan. Östersund: ITPS.

Highsmith, James A.

ITPS

2004 Agile project management : creating innovative products. Boston, MA: Addison-Wesley.

2004a The EC Regional Structural Funds impact in Sweden 1995-2000. Östersund: Swedish Institutes for Growth Policy Studies.

2004b Effektutvärdering av de geografiska målprogrammen inom EG:s strukturfonder. Östersund: ITPS.

Larson, Andrea

1992 Network Dyads in Entrepreneurial Settings: A study of the Governance of Exchange Relationships. Administrative Science Quarterly 37(1).

Metcalfe, J.S.

1997 Science policy and technology policy in a competitive economy. International Journal of

NUTEK Social Economics 24(7):723-740.

2004 Tillsammans utvecklar vi Sverige: NUTEK 043-2004.

2005 Organisera för näringslivets medverkan: NUTEK B 2005-5.

NUTEK, and VINNOVA

2002 Hur arbetar man med regionala företagsnätverk? : erfarenheter från ett regionalt programarbete. Stockholm: Verket för näringslivsutveckling (NUTEK) : Verket för innovationssystem (VINNOVA).

Parker, Peter

2004 How Personal Networks Shape Business: an Anthropological Study of Social Embeddedness, Knowledge Development and Growth of Firms. Volume 14. Lund: Dept. of Sociology, Lund University.

Porter, Michael

1990 The Competitive Advantage of Nations. New York: Free Press.

Ring, P.S., and A.H. Van de Ven

1994 Developmental processes of cooperative interorganizational relationships. Academy of Management Review 19(1):90-118.

Saxenian, Analee 2000 Regional Advantage: Culture and Competition in Silicon Valley and Rt. 128. Cambridge MA: Harvard University Press.

Schwaber, Ken 2004 Agile Project Management with Scrum: Microsoft Press.

Tjäder, Jimmy, and Jonas Söderlund 2001 Ledning av IT-projekt. In Projekt: organisation för målorientering och lärande. Pp. 7598. Lund: Studentlitteratur. 